\title{
The Construction of University Laboratories under the Linkage Mechanism of "Point and Line to Plane"
}

\author{
Xie-qiu Zhao ${ }^{1}$, Pin-xuan Jiang, ${ }^{2, *}$ \\ ${ }^{1}$ College of Computer Science and Technology,Beihua University \\ ${ }^{2}$ Beihua University \\ *Corresponding author:Pin-xuan Jiang
}

Keywords: University, Laboratory, Point and Line to Plane, Linkage.

\begin{abstract}
With the in-depth study on the spirits of "the theoretical and practical issues of party building", it is to form the linkage mechanism of "Point and Line to Plane" of the development and construction idea of university laboratories. It has far-reaching significance to improve the university laboratory teaching and scientific research management level. It has the responsibility, democracy and standardized and professional characteristics for the development of laboratory construction in colleges and universities under the linkage mechanism of "Point and Line to Plane". Renewing the concept of laboratory management, strengthening the composition of laboratory personnel, optimizing the school and laboratory system, and improving the management level of laboratory equipment are effective ways for the innovation and development of laboratory in Colleges and universities.

In recent years, with the rapid development of China's higher education, teaching and Research on the construction of infrastructure investment in Colleges and universities continue to increase, the laboratory construction in Colleges and universities has become the focus of attention to the content of the infrastructure update perfect. University laboratory is a multi-functional place service based on experimental teaching and scientific research, at the same time the students' independent innovation ability and practice ability for the training, also provides an important platform for the national high level science and technology research and development. Therefore, the construction and management of the laboratory as an important content of the connotation construction of colleges and universities is an effective way to improve the quality of teaching and innovative reform in Colleges and universities.
\end{abstract}

\section{The construction of the Linkage Mechanism of "Point and Line to Plane"of the meaning of the laboratory}

In February 2015, in the seminar on the the fourth Plenary Session of the 18th CPC Central Committee spirit of the party, General Secretary Xi put forward the concept of "key minority". He stressed that leading cadres at all levels shoulder an important responsibility in promoting the rule of law, and comprehensively governing the country according to law must seize the key minority of leading cadres". The key a few the concept into a "point" understanding into the management innovation lab construction in Colleges and universities is a new idea of management in university laboratory construction, the leading cadres of the party organization of the theoretical study, and constantly improve the leading cadres at all levels of responsibility, and the construction and development of laboratory shoulder the responsibilities of leadership, innovation and development laboratory. In February 2016, the CPC Central Committee issued "on the" learning, learning series speech at the party constitution all Party members, Party members to be qualified "learning education program" deployment, carry out the "two a" learning education, put forward the ideological education in the first place. The construction and development of university laboratory 
as an opportunity, the "two learning and one doing" learning as a carrier of development and construction, the innovation of laboratory construction, that is, into the laboratory innovation construction thought line". "The party strictly to every Party branch is the general secretary Xi Jinping to carry out the" two a "study and education made important instructions that will be integrated into the core idea to improve the rapid development of construction in the laboratory contributes to the overall level of University laboratory. The university laboratory branch to carry out theoretical study, improve their service consciousness, sense of responsibility and sense of innovation, and ultimately improve the laboratory research and teaching ability, this process can be summarized as "surface definition". Therefore, the linkage mechanism of "point", "line" and "surface" is the fundamental way to construct innovative laboratory.

\section{The characteristics of the construction and development of the Linkage Mechanism of "Point and Line to Plane”}

Accountability and Democratization. The laboratories of colleges and universities in our country generally implement three levels of management in schools, colleges and laboratories. The school management mainly for equipment procurement and purchasing equipment, making the entire laboratory and development direction of the construction of the laboratory work. From the macro point of view to grasp the development of the laboratory, the integration of resources in all aspects, so that the laboratory has become more efficient, more comprehensive. And the laboratory itself is responsible for the implementation of the director system, determined by the school candidates, responsible for the daily work of the usual laboratory, as well as the experimental major academic activities, responsible for determining the laboratory's future tasks, goals and so on. The source of our university laboratory funds are similar, generally divided into national project funds, project, funding, school allocated operating expenses, the international cooperation project funds, enterprise cooperation funds, external testing service fees. Although it seems clear and clear, but the amount of money is huge, more rigorous management is needed. In order to make the laboratory construction more comprehensive, we should choose the incentive way to manage it. For example, in the distribution, to key positions and major projects and excellent talent tilt, so that all members of the enthusiasm greatly improved. Laboratory construction and daily experiments need more capital flow, so the funds need to find special personnel management, and make the funds management transparent and democratic. To report regularly, most of the members agree when a larger amount of expenditure is made.

Standardization and specialization. With the development of science and technology, the work of university laboratory is linked with the computer, and the management of network and intelligence is realized. The advantages of network and intelligent network obviously, which can enable the sharing of resources, improve efficiency in the use of the laboratory, but also makes the professional to the needs of the laboratory average, the professional can be balanced. In general, the laboratory can use the network and their own management system so that all the teachers and students can know the use of the instrument and use, also can let the teachers and students can learn new equipment or new research laboratory, also can master to open each laboratory. And also can set up professional staff on the network to answer the question of teachers and students who do not know the above issues, but also on the network with the laboratory staff to communicate and explore. Greatly reduce the workload of staff, but also can greatly enhance the efficiency of the laboratory, the laboratory can also facilitate the statistics used in the laboratory, the laboratory for later development of construction to provide data to help. The work and organization of key laboratories in Colleges and universities should have professional knowledge and professional skills, and be able to learn new technologies and knowledge with the development of the times. The professionalism of laboratory research team is mainly embodied in not only the skilled operation of laboratory equipment, but also the development of new functions, in order to adapt to various new research and teaching work. 
Under the Linkage Mechanism of "Point and Line to Plane"it is the effective way for laboratory construction in Colleges and Universities

Updating the concept of laboratory management in Colleges and Universities. At present, laboratory management in Colleges and universities has become a point restricting the quality of teaching in Colleges and universities, the traditional laboratory management has been unable to meet the current teaching needs. The revolution of laboratory management in Colleges and universities must be put on the agenda. The concept of laboratory management must be updated in Colleges and universities. If we want to train talents, we must walk out from the former laboratory management mode. Only the continuous introduction of new management mode, can make the rapid development of the laboratory. For example, the theory of knowledge management can be applied to the theoretical system of university laboratories to train innovative talents for University laboratories.

Strengthen the composition of laboratory personnel. The knowledge level and technical level of laboratory personnel directly affect the management level of laboratory. In view of the current most universities face a severe shortage of laboratory personnel and the level of technology needs to improve the situation, the university should hand through the introduction of some excellent teachers and graduate students in the lab formulate related policies have had similar experiences can give priority to the introduction, in order to meet the demand for University laboratory personnel. On the other hand, due to the frequent replacement of laboratory equipment, and in order to broaden their horizons and innovation ability of laboratory personnel, should conduct regular training of laboratory staff training by laboratory personnel sent to the famous university laboratory, to enrich themselves and create more value, enhance the level of laboratory.

Optimize the school and laboratory system. In order to promote the development and construction of university laboratories, universities should also set up a unique system for the laboratory to train talents. Universities should pay more attention to the laboratory and give information feedback regularly. Laboratory internal management needs a set of reasonable rules and regulations. Through the incentive system, including to mobilize the enthusiasm and creativity of the laboratory personnel performance evaluation and job responsibility assessment, to concentrate resources to cultivate talents, the formation of benign flow management personnel, the system continue to explore their own potential laboratory personnel, create more scientific research achievements.

Improving the management level of laboratory equipment in Universities. In the purchase of equipment, be sure to make the best use of it, to avoid duplication, idle and so on, in order to improve the utilization rate of equipment and develop its maximum value. In the safety of the use of equipment, the equipment should be tested and maintained regularly, so as to avoid the phenomenon of personnel injury caused by the experimental instrument. At the same time the exclusive service system of some of the instruments, the responsibility directly applies to everyone, in order to avoid the adverse consequences caused by improper operation.

\section{Acknowledgements}

The paper is the topic of party construction of Beihua university: The achievement of linking mechanism research of One point to promote the whole area to play the main role of party branch of colleges and universities.

\section{References}

[1] Guo Tao, Xie Kun. The exploration and practice of university laboratory construction of [J]. laboratory research and exploration, 2013,32 (09): 222-224+254.

[2] Zhang Caihong, Xu Hongshan, Yu Lan Jihong, Chunsheng, Zhang Wanguang. From the perspective of university laboratory development path [J]. experimental technology and management to cultivate innovative talents, 2013,30 (07): 188-192+197. 
[3] Meng Zhaoxia. Research and Exploration on innovative laboratory management of university laboratory [J]., 2013,32 (06): 202-205.

[4] Wu Lanlan. Construction and practice of laboratory team in Colleges and universities [J]. laboratory research and exploration, 2012,31 (11): 167-169+188.

[5] Jiang Liwei. Reform and exploration of laboratory management system in Colleges and universities [J]. laboratory research and exploration, 2012,31 (06): 193-195. 